\title{
An observational study to assess changes in social inequality in smoking-attributable upper aero digestive tract cancer mortality among Canadian males between 1986 and 2001
}

\author{
Sonica Singhal ${ }^{1 *}$, Carlos R Quiñonez ${ }^{1}$ and Prabhat Jha ${ }^{2,3}$
}

\begin{abstract}
Background: Tobacco and low socioeconomic status have been acknowledged as potential risk factors for upper aero-digestive tract (UADT) cancers in North America. In context of reducing adult male smoking prevalence (by over 50\%), in the past few decades in Canada, this study tried to document changes in smoking-attributable UADT cancer mortality rates, among Canadian males of different social strata, between 1986 and 2001.

Methods: The contribution of smoking to UADT cancer mortality was estimated indirectly by using lung cancer mortality as an indicator of the accumulated mortality from smoking in a population. This method was applied to UADT cancer death rates of 35-69 year old socially stratified males. Data, stratified by neighborhood income quintile, could be obtained from Statistics Canada, for four census years, 1986, 1991, 1996, and 2001.

Results: A total of 2704 male deaths were analyzed. Between 1986 and 2001, UADT cancer deaths reduced by 30\% ( 32 to 22 per 100,000) but the proportion of these deaths attributable to smoking reduced much more, by $41 \%$ ( 22 to 13 per 100,000). In the span of fifteen years, absolute social inequality (measured by rate difference between the highest and the lowest stratum) in smoking-attributable male UADT cancer mortality in Canada reduced by $47 \%$ and relative social inequality (measured by rate ratios) reduced by $9 \%$.

Conclusion: The present analyses reveal that between 1986 and 2001, smoking-attributable UADT cancer mortality rates among adult males (35-69 years) in Canada reduced in all social strata and the social inequalities in these rates have narrowed. Analysis of more current data will be of interest to confirm these trends.
\end{abstract}

Keywords: Smoking, Upper aero-digestive tract cancer, Socioeconomics, Mortality

\section{Background}

The sixth most common cancers, to occur worldwide, are the cancers of upper aero-digestive tract (UADT), accounting for approximately five percent of all malignancies [1]. The poor prognosis [2], occurrence of additional cancers of the same or related sites [3], a low five-year survival rate (overall approximately $64 \%$ with variation depending on the site) [4], and the economic burden to the health care system and society [5] make

\footnotetext{
* Correspondence: sonica.singhal@mail.utoronto.ca

'Community Dental Health Services Research Unit, Discipline of Dental Public Health, Faculty of Dentistry, University of Toronto, Toronto, ON M5G 1G6, Canada

Full list of author information is available at the end of the article
}

such cancers a serious public health concern. The burden of these cancers is more prevalent in males; a study looking at the trends of these cancers in Ontario, Canada, found UADT cancers to be three times more prevalent in males as compared to females and this ratio remained constant from 1984 to 2001 [6]. Tobacco [7-10] and low socioeconomic status [2,11-13] have been acknowledged as risk factors for UADT cancers; approximately, $65 \%$ of all UADT cancers are attributable to smoking [14].

The prevalence of smoking in adult males has decreased by over fifty percent in the past few decades in highincome countries, including Canada and the US [15], but most of these countries have observed the greatest declines among higher social strata $[16,17]$. Concern arises

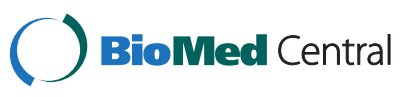


if these declines in smoking prevalence have similar or different effects on smoking-attributable mortality rates for males of different social strata [17]. In the US, death rates due to cancer of the mouth and pharynx fell from 1993 to 2007, but the declines were largely limited to those with higher educational attainment [12]. We know of no similar study in Canada; specifically, there has been no study that quantifies changes in UADT cancer mortality attributable to smoking in different social strata. Thus the aim of this paper is to describe changes in smokingattributable UADT cancer mortality among Canadian males of different social strata between 1986 and 2001.

\section{Methods}

The approximate contribution of smoking to UADT cancer mortality among Canadian males was estimated indirectly by a method, developed by Peto et al. [18], which has been adapted to analyze social-stratum specific death rates from smoking [19]. This method uses lung cancer mortality as an indicator of the accumulated mortality from smoking in a population [20], and can therefore be used to determine the proportions of smoking-attributable mortalities from other smoking-related diseases, such as UADT cancers [21].

We applied these methods to UADT cancer death rates of 35-69 year old Canadian males of urban Canada (census metropolitan areas, which constitute 60\% of male population of Canada), for four census years; 1986, 1991, 1996, and 2001. We obtained 5-year age, sex, and disease-specific mortality data for different social strata, for the four census years, from Statistics Canada. We also obtained population count for the four respective years. These data at Statistics Canada are collected from the Canadian Mortality Data Base and population census, respectively. Data included populations living in institutions as well and were satisfactorily complete. Data obtained were socially stratified by neighborhood income quintile [20], which is determined by the percentage of population in their neighbourhood below the low-income cut-offs [20]. Quintiles of population were ranked from the lowest to the highest as: poorest, poorer, average, richer, and richest, respectively. The use of neighborhood level information was considered reasonable as past studies have argued for the validity of using neighborhood income quintiles as a proxy for individual socioeconomic status [20,22]. Metropolitan areas were used because neighborhoods are more clearly defined and residential segregation by income is more pronounced in big cities than in small towns and rural areas [23].

In the absence of any nationally representative study of smoking and mortality rates, CPS II study (a prospective cohort study of one million Americans, conducted during 1980's, called the Cancer Prevention Study II) was considered as the reference population, from which lung cancer mortality rates of smokers and never-smokers, and the relative risks for the UADT cancers were considered. For women, as the consequences of smoking epidemic were still to develop in 1980's [24,25], relative risks from CPS-II study have a probability of giving conservative estimates of smoking-attributable mortality rates. Therefore, to prevent underestimation, analysis for women was excluded. Briefly, the steps included [19] are as follows : 1) The absolute age-specific lung cancer rates for 35-69 years old Canadian males of each social stratum were calculated; 2 ) These lung cancer rates were matched to the lung cancer rates in a mixture of smokers and non-smokers in CPS II study; 3) The proportion of lung cancer mortality attributed to smoking was used as a guide (with halving of excess mortality ratio to have conservative estimates) to estimate the smoking-attributed proportion of the mortality from UADT cancers. Considering that calculation of population-attributable fractions by conservative halving of excess risk substantially lowers the excess risk when the proportions of smokers are less but do not affect the estimates when the proportions are higher [18]; to be sure that the conservative halving does not accentuate the differences across social strata, data were analyzed both ways, with halving and without (data not shown). The results revealed that the fear was unfounded and therefore, to have conservative estimates we continued with halving of the excess risks.

Cause of death was coded according to the International Classification of Diseases (ICD-9 for 1986, 1991, and 1996 and ICD-10 for 2001). The UADT cancer sites included cancers of the lip, tongue, gums, floor of the mouth, salivary glands, tonsils, oro-pharynx, naso-pharynx, hypopharynx, oesophagus, larynx, glottis and epiglottis $[4,6,26]$. All-cause and smoking-attributable mortality rates for UADT cancers were assessed for all income quintiles. The rates assessed for the richest and richer, and middle and poorer quintiles were quite comparable (data not reported). As the number of smoking-attributable deaths was low in these quintiles, data for these quintiles were combined forming three social strata and re-analysis was done. Final analysis presented data subdividing quintiles into three strata as the highest $40 \%$, middle $40 \%$, and the lowest $20 \%$. Social inequalities were measured using simple and straight forward measures, such as rate ratios and rate differences. Statistical Analysis Software (SAS 9.0) was used for data analyses. Research ethics approval was obtained from the University of Toronto.

\section{Results}

A total of 2704 male deaths, at ages $35-69$ years, due to UADT cancers were analyzed for four time points; 1986 , 1991, 1996, and 2001. The present analysis showed (Figure 1) an overall mortality reduction trend due to UADT cancers among adult males in the metropolitan 


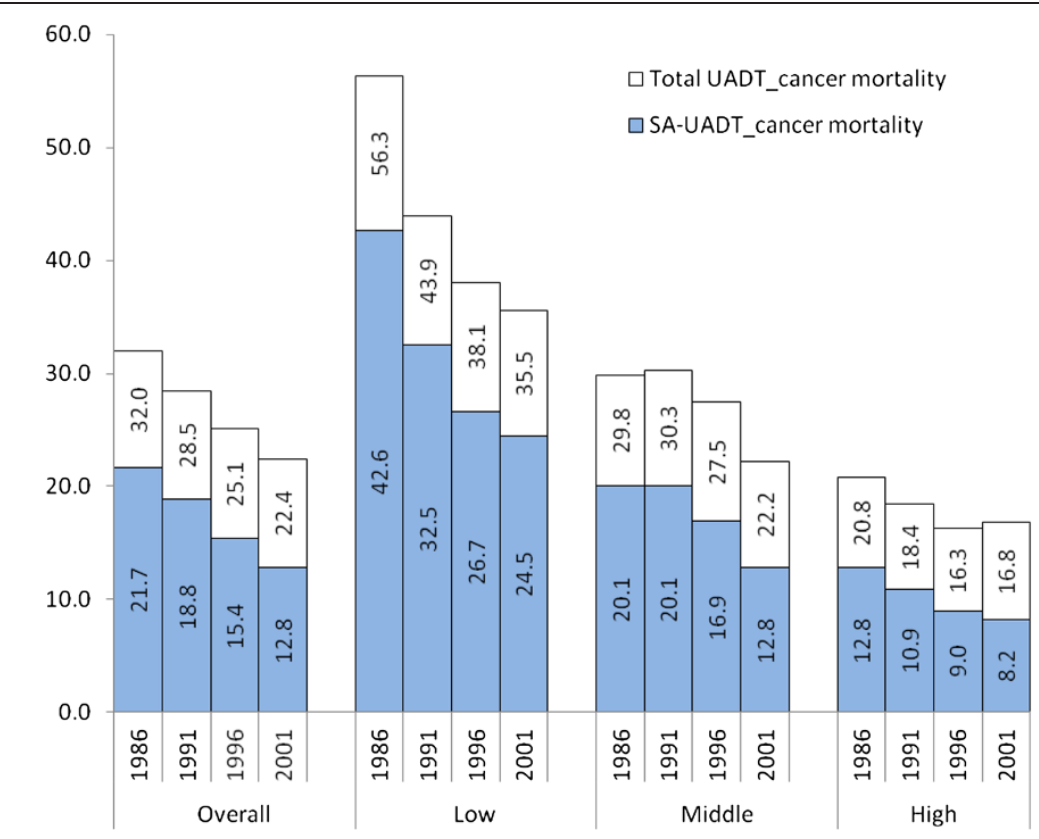

Figure 1 Total and smoking-attributable UADT cancer mortality rates per 100,000 males, by neighborhood income quintile.

areas of Canada, between 1986 and 2001. Table 1 provides, estimated male death rates due to UADT cancers attributed and not attributed to smoking, which together add up to total annual death rate per 100,000 males. Between 1986 and 2001, overall UADT cancer death rates fell by $30 \%$ (32 to 22 per 100,000 ) and the death rates attributable to smoking fell by $41 \%$ (22 to 13 per 100,000). Men of the lowest stratum had the highest UADT cancer death rate (56 per 100,000) in 1986. By 2001, UADT cancer deaths fell by $37 \%$ (56 to 36 per $100,000)$ and smoking-attributable proportions fell by $42 \%$ (43 to 25 per 100,000 ) in the lowest stratum. In the middle stratum, UADT cancer deaths fell by $27 \%$ (30 to 22 per 100,000) and smoking-attributable proportions fell by $35 \%$ (20 to 13 per 100,000). In the highest stratum, UADT cancer deaths fell only by $19 \%$ (21 to 17 per 100,000); however, smoking-attributable proportions fell by $38 \%$ (13 to 8 per 100,000 ), which were comparable to other strata.

Table 2 provides changes in absolute and relative social inequalities in UADT cancer death rates between 1986 and 2001. In 1986, 36 more deaths per 100,000 due to UADT cancers occurred in the lowest stratum as compared to the highest, out of which 30 deaths were attributable to smoking. By 2001, absolute inequalities reduced as total rate difference between the highest and the lowest stratum fell by $47 \%$ (19 more deaths per 100,000 among the lowest stratum as compared to the highest stratum) and smoking-attributable proportions also fell by $47 \%$ (16 more deaths per 100,000 among the lowest stratum as compared to the highest stratum).
In 1986, total death rate due to UADT cancers was 2.7 times more in the lowest stratum as compared to the highest. The proportional differences between social strata in smoking-attributed mortality were, however, more extreme at 3.3. By 2001, relative inequalities also reduced as total death rate ratios between the highest and the lowest stratum fell by $22 \%$ (2.7 in 1986 to 2.1 in 2001) and smoking-attributable death rate ratios fell by 9\% (3.3 to 3.0) between 1986 and 1991 and remained constant at 3.0 from 1991 to 2001.

\section{Discussion}

This is a descriptive analysis of trends in UADT cancer adult male mortality rates attributed to smoking among neighborhood income quintiles in urban Canada. The analysis reveals that between 1986 and 2001 UADT cancer mortality fell in all quintiles and the reductions were comparable in all quintiles. Within the quintiles, reduction in smoking-attributable proportions of UADT cancer deaths were more pronounced.

According to the Peto method, the prevalence of smoking in the study population was estimated indirectly from lung cancer death rates of the population [18]. This indirect method substitutes observed current exposure of smoking estimates with prevalence of smoking that is considered necessary for causing the current lung cancer mortality burden [27]. For most smoking-related outcomes, the current burden of disease is largely influenced by the past smoking exposure in the population $[28,29]$. The prevalence estimates calculated through this method avoids the potential error resulting from the lag time 
Table 1 Annual death rates, per 100,000 men aged 35-69 years, due to UADT cancer, attributed to smoking or not, by neighborhood income quintile, together with the stratum specific number of deaths due to lung cancer and UADT cancer and the population count, respectively

\begin{tabular}{|c|c|c|c|c|}
\hline & Overall & Lowest $^{\neq}$ & Middle $^{\neq}$ & Highest $^{\ddagger}$ \\
\hline \multicolumn{5}{|l|}{1986} \\
\hline Yes* & 21.7 & 42.6 & 20.1 & 12.8 \\
\hline $\mathrm{No}^{* *}$ & 10.3 & 13.7 & 9.7 & 8.0 \\
\hline Total & 32.0 & 56.3 & 29.8 & 20.8 \\
\hline Total UADT cancer deaths & 683 & 258 & 258 & 167 \\
\hline Total lung cancer deaths & 2744 & 830 & 1117 & 797 \\
\hline Population & 2789815 & 532395 & 1091295 & 1166125 \\
\hline \multicolumn{5}{|l|}{1991} \\
\hline Yes $^{*}$ & 18.8 & 32.5 & 20.1 & 10.9 \\
\hline $\mathrm{No}^{* *}$ & 9.6 & 11.4 & 10.2 & 7.5 \\
\hline Total & 28.5 & 43.9 & 30.3 & 18.4 \\
\hline Total UADT cancer deaths & 680 & 208 & 306 & 166 \\
\hline Total lung cancer deaths & 2881 & 830 & 1237 & 814 \\
\hline Population & 3244930 & 593665 & 1283315 & 1367950 \\
\hline \multicolumn{5}{|l|}{1996} \\
\hline Yes* $^{*}$ & 15.4 & 26.7 & 16.9 & 9.0 \\
\hline $\mathrm{No}^{* *}$ & 9.7 & 11.4 & 10.6 & 7.3 \\
\hline Total & 25.1 & 38.1 & 27.5 & 16.3 \\
\hline Total UADT cancer deaths & 665 & 188 & 298 & 179 \\
\hline Total lung cancer deaths & 2608 & 696 & 1092 & 820 \\
\hline Population & 3679785 & 679915 & 1431225 & 1568645 \\
\hline \multicolumn{5}{|l|}{2001} \\
\hline Yes $^{*}$ & 12.8 & 24.5 & 12.8 & 8.2 \\
\hline $\mathrm{No}^{* *}$ & 9.6 & 11.0 & 9.4 & 8.6 \\
\hline Total & 22.4 & 35.5 & 22.2 & 16.8 \\
\hline Total UADT cancer deaths & 676 & 187 & 269 & 220 \\
\hline Total lung cancer deaths & 2487 & 673 & 1041 & 773 \\
\hline Population & 4205285 & 778220 & 1628620 & 1798445 \\
\hline
\end{tabular}

*UADT cancer mortality attributable to smoking, ${ }^{* *}$ not attributable to smoking.

Average lung cancer rates for 35-69 year old male smokers of CPS II study was 22.2 per 100,000 and for non-smokers the rates were 6 per 100,000.

$\neq$ Neighborhood income quintile divided in lowest = poorest, middle = poorer + middle, and highest $=$ richer + richest .

between population changes in smoking prevalence and the resulting change in disease outcome [27].

Excess risks were arbitrarily halved to calculate smoking-attributable fractions conservatively as some of the deaths can be attributed to other risk factors, such as alcohol and Human Papilloma virus infection. As the methods used have been acknowledged to be crude, presentation of apparently precise numbers should not be taken to suggest otherwise [18]. The statistical significance of the observed trends in smoking-attributable
Table 2 Social inequality in UADT cancer mortality rate between the lowest and the highest neighborhood income quintile and the proportion of deaths attributable to smoking

\begin{tabular}{|c|c|c|c|c|c|}
\hline & \multicolumn{2}{|c|}{ Social inequality } & \multicolumn{3}{|c|}{$\begin{array}{c}\% \text { of smoking-attributable } \\
\text { deaths }\end{array}$} \\
\hline & $\begin{array}{c}\text { Rate ratio } \\
\text { (Lowest/ } \\
\text { Highest) }\end{array}$ & $\begin{array}{l}\text { Rate difference } \\
\text { (Lowest-Highest) }\end{array}$ & Lowest $^{\ddagger}$ & Highest $^{\neq}$ & Overall \\
\hline \multicolumn{6}{|l|}{1986} \\
\hline Yes* & 3.3 & 29.8 & 76 & 62 & 68 \\
\hline $\mathrm{No}^{* *}$ & 1.7 & 5.7 & & & \\
\hline Total & 2.7 & 35.5 & & & \\
\hline \multicolumn{6}{|l|}{1991} \\
\hline Yes* & 3.0 & 21.6 & 74 & 59 & 66 \\
\hline $\mathrm{No}^{* *}$ & 1.5 & 3.9 & & & \\
\hline Total & 2.4 & 25.5 & & & \\
\hline \multicolumn{6}{|l|}{1996} \\
\hline Yes* & 3.0 & 17.7 & 70 & 55 & 61 \\
\hline $\mathrm{No}^{* *}$ & 1.6 & 4.1 & & & \\
\hline Total & 2.3 & 21.8 & & & \\
\hline \multicolumn{6}{|l|}{2001} \\
\hline Yes* & 3.0 & 16.3 & 69 & 49 & 57 \\
\hline $\mathrm{No}^{* *}$ & 1.3 & 2.4 & & & \\
\hline Total & 2.1 & 18.7 & & & \\
\hline
\end{tabular}

*UADT cancer mortality attributable to smoking, ${ }^{* *}$ not attributable to smoking.

₹ Neighborhood income quintile divided in lowest $=$ poorest, middle $=$ poorer + middle, and highest $=$ richer + richest .

mortality rates were also not assessed using any method like weighted regression analysis, as the motive was to look at the trends of these rates in general in different social strata of Canada. The major pattern is, however, clear that smoking-attributable UADT cancer mortality is reducing among all social strata of Canada. This is in consensus with steady declines in male smoking prevalence (15 years and above) in Canada over the last five decades; the rates reduced from $61 \%$ in 1965 to $20 \%$ in 2010 [30]. The trends observed here are in agreement with a study done by Gupta et al. in Canada, and the US, which stated that the incidence of UADT cancers reduced between 1984 and 2001 [6]. A possible explanation of this reduction can be tobacco control policies (for example significant increase in tobacco taxes in 1980's and early 1990's) which were implemented at that time period affecting the smoking prevalence. The results observed are also in consensus with Reid et al., who observed smoking prevalence among different social strata in Canada, 1999-2006, also revealed absolute reductions in daily smoking and cigarettes consumed per day in both the highest and the lowest social strata [16].

For the analysis, the relative risk of smoking-attributable UADT cancer mortality was considered the same across 
all quintiles; however, there are many factors other than smoking that differ between quintiles [31] and as smoking interacts with other risk factors [32], the hazard for the individual smoker must also be expected to be different across various quintiles. However, Thun et al., for a US study, determined that smoking-attributable deaths reduced by just $1 \%$ per year after adjusting for other factors like education, occupation, race, alcohol consumption, and various dietary factors, in addition to age and sex [33].

Because of lack of any large national representative mortality study, usage of relative risks based on CPS II study was another limitation; however, the mortality risks of CPS II study for various diseases have been quite acceptable in the Canadian context. Another limitation was the use of neighborhood level information, instead of family or individual, and applying to individuals, which forces consideration of the ecological fallacy. However, past studies have argued for the validity of using income quintiles as a proxy for individual socioeconomic status $[20,22]$.

Mackenback and Kunst, in 1997, presented a framework for measuring the magnitude of socio-economic inequalities in health, according to which, simple and straightforward measures are more useful in informing policy makers [34]. Relative Index of Inequality (RII), Slope Index of Inequality (SII), and Concentration Index on the other hand have a complex interpretation and can easily lead to misunderstandings [34]. Therefore, we used rate ratios and rate differences to depict social inequalities.

Although the methods of estimation used are indirect and have some limitations, the uncertainties inherent in these methods affect all social strata similarly; therefore, cannot account for overestimation of the differences observed between social strata in smoking-attributed mortality.

\section{Conclusion}

Between 1986 and 2001, the social inequalities in smoking-attributable UADT cancer mortality rates among adult males (35-69 years) in Canada have narrowed. In context of implementation of different tobacco control policies in the past two decades, assessment of smoking-attributable rates of more recent years would be of interest to confirm the trends observed.

\section{Abbreviation \\ UADT: Upper aero-digestive tract.}

\section{Competing interest}

We declare that we have no financial or non-financial competing interest.

\section{Authors' contributions}

SS, CQ, and PJ planned the paper. SS and PJ obtained data. SS performed all statistical analyses. All authors participated in interpreting the results and contributed equally in writing the manuscript. All authors read and approved the final manuscript.

\section{Acknowledgements}

We acknowledge the support of Mr. Russell Wilkins at Statistics Canada, for compilations of data and preparing data to our specifications.

\section{Author details}

'Community Dental Health Services Research Unit, Discipline of Dental Public Health, Faculty of Dentistry, University of Toronto, Toronto, ON M5G 1G6, Canada. ${ }^{2}$ Centre for Global Health Research, Li Ka Shing Knowledge Institute, St. Michael's Hospital, Toronto, Canada. ${ }^{3}$ Dalla Lana School of Public Health, University of Toronto, Toronto, Canada.

Received: 13 August 2012 Accepted: 2 April 2013

Published: 10 April 2013

\section{References}

1. Devins GM, Otto KJ, Irish JC, Rodin GM (Eds): Psycho-oncology, chapter 17, head and neck cancer second edition. New York: Oxford University Press; 2010.

2. Al-Dakkak I, Khadra M: Socio-economic status and upper aerodigestive tract cancer. Evid Based Dent 2011, 12:87-88.

3. Franco EL: Multiple cancers of the upper aero-digestive tract: the challenge of risk factor identification. Cancer Lett 1991, 60:1-8.

4. Hoffman HT, Karnell LH, Funk GF, Robinson RA, Menck HR: The national cancer data base report on cancer of the head and neck. Arch Otolaryngol Head Neck Surg 1998, 124:951-962

5. Virgo KS, Paniello RC, Johnson FE: Costs of posttreatment surveillance for patients with upper aerodigestive tract cancer. Arch Otolaryngol Head Neck Surg 1998, 124:564-572.

6. Gupta S, Kong W, Peng Y, Miao Q, Mackillop WJ: Temporal trends in the incidence and survival of cancers of the upper aerodigestive tract in Ontario and the united states. Int J Cancer 2009, 125:2159-2165.

7. Ligier K, Belot A, Launoy G, Velten M, Bossard N, Iwaz J, Righini CA, Delafosse P, Guizard AV: Descriptive epidemiology of upper aerodigestive tract cancers in France: incidence over 1980-2005 and projection to 2010. Oral Oncol 2011, 47:302-307.

8. Szymanska K, Hung RJ, Wunsch-Filho V, Eluf-Neto J, Curado MP, Koifman S, Matos E, Menezes A, Fernandez L, Daudt AW, et al: Alcohol and tobacco, and the risk of cancers of the upper aerodigestive tract in Latin America: a case-control study. Cancer Causes Control 2011, 22:1037-1046.

9. Anantharaman D, Marron M, Lagiou P, Samoli E, Ahrens W, Pohlabeln H, Slamova A, Schejbalova M, Merletti F, Richiardi L, et al: Population attributable risk of tobacco and alcohol for upper aerodigestive tract cancer. Oral Oncol 2011, 47:725-731.

10. Zeka A, Gore R, Kriebel D: Effects of alcohol and tobacco on aerodigestive cancer risks: a meta-regression analysis. Cancer Causes Control 2003, 14:897-906.

11. Conway DI, McKinney PA, McMahon AD, Ahrens W, Schmeisser N, Benhamou S, Bouchardy C, Macfarlane GJ, Macfarlane TV, Lagiou P, et al: Socioeconomic factors associated with risk of upper aerodigestive tract cancer in Europe. Eur J Cancer 2010, 46:588-598.

12. Chen AY, Desantis $C$, Jemal A: US mortality rates for oral cavity and pharyngeal cancer by educational attainment. Arch Otolaryngol Head Neck Surg 2011, 137:1094-1099.

13. Skarsgard DP, Groome PA, Mackillop WJ, Zhou S, Rothwell D, Dixon PF, O'Sullivan B, Hall SF, Holowaty EJ: Cancers of the upper aerodigestive tract in Ontario, Canada, and the united states. Cancer 2000, 88:1728-1738.

14. Parkin DM: Tobacco-attributable cancer burden in the UK in 2010. Br J Cancer 2011, 105(S2):S6-S13.

15. Forey B, Hamling J, Lee P (Eds): International smoking statistics. A collection of historical data from 30 economically developed countries. New York: Oxford Univ. Press; 2009.

16. Reid JF, Hammond D, Driezen P: Socio-economic status and smoking in Canada, 1999-2006: has there been any progress on disparities in tobacco use? Can J Public Health 2010, 101:73-78.

17. Giskes K, Kunst AE, Benach J, Borrell C, Costa G, Fau CG, Dahl E, Dalstra JAA, Federico $B$, Helmert $U$, Judge $K$, et al: Trends in smoking behaviour between 1985 and 2000 in nine European countries by education. J Epidemiol Community Health 2005, 59:395-401.

18. Peto R, Lopez AD, Boreham J, Thun M, Heath C: Mortality from tobacco in developed countries: indirect estimation from national vital statistics. Lancet 1992, 339:1268-1278. 
19. Jha P, Peto R, Zatonski W, Boreham J, Jarvis MJ, Lopez AD: Social inequalities in male mortality, and in male mortality from smoking: indirect estimation from national death rates in England and Wales, Poland, and north America. Lancet 2006, 368:367-370.

20. Ng E, Wilkins R, Fung MF, Berthelot JM: Cervical cancer mortality by neighbourhood income in urban Canada from 1971 to 1996. CMAJ 2004, 170:1545-1549.

21. Pérez-Ríos M, Montes A: Methodologies used to estimate tobacco-attributable mortality: a review. BMC public health 2008, 8:22.

22. Roos NP, Mustard CA: Variation in health and health care use by socioeconomic status in Winnipeg, Canada: does the system work well? Yes and no. Milbank Q 1997, 75:89-111.

23. Steenland K, Henley J, Thun M: All-cause and cause-specific death rates by educational status for two million people in two American cancer society cohorts, 1959-1996. Am J Epidemiol 2002, 156:11-21.

24. Boyle P: Cancer, cigarette smoking and premature death in Europe: a review including the recommendations of European cancer experts consensus meeting, Helsinki, October 1996. Lung Cancer 1997, 17:1-60.

25. Barbara Montgomery Dossey LK: Holistic nursing: a handbook for practice fifth edition. American Holistic Nurses' Association: Jones and Barlett Publishers:561.

26. Muir C, Weiland L: Upper aerodigestive tract cancers. Cancer 1995, 75:147-153.

27. Tanuseputro P, Manuel D, Schultz S, Johansen H, Mustard C: Improving population attributable fraction methods: examining smokingattributable mortality for 87 geographic regions in Canada. Am J Epidemiol 2005, 161:787.

28. Bray F, Tyczynski JE, Parkin DM: Going up or coming down? the changing phases of the lung cancer epidemic from 1967 to 1999 in the 15 European union countries. Eur J Cancer 2004, 40:96-125.

29. Brennan P, Bray l: Recent trends and future directions for lung cancer mortality in Europe. Br J Cancer 2002, 87:43-48.

30. Reid JL, Hammond D, Burkhalter R, Ahmed R: Tobacco Use in Canada: patterns and trends, 2012 edition. Waterloo,ON: Propel Centre for PopulationHealth Impact,University of Waterloo. http://www.tobaccoreport. ca/2012/TobaccoUseinCanada_2012.pdf.

31. Banks J, Marmot M, Oldfield Z, Smith JP: Disease and disadvantage in the United States and in England. JAMA 2006, 295:2037-2045.

32. Doll R, Peto R: The causes of cancer: quantitative estimates of avoidable risks of cancer in the United States today. J Natl Cancer Inst 1981, 66:1191-1308.

33. Thun MJ, Apicella LF, Henley SJ: Smoking vs other risk factors as the cause of smoking-attributable deaths: confounding in the courtroom JAMA 2000, 284:706-712.

34. Mackenbach JP, Kunst AE: Measuring the magnitude of socio-economic inequalities in health: an overview of available measures illustrated with two examples from Europe. Soc Sci Med 1997, 44:757-771.

doi:10.1186/1471-2458-13-328

Cite this article as: Singhal et al: An observational study to assess changes in social inequality in smoking-attributable upper aero digestive tract cancer mortality among Canadian males between 1986 and 2001. BMC Public Health 2013 13:328.

\section{Submit your next manuscript to BioMed Central and take full advantage of:}

- Convenient online submission

- Thorough peer review

- No space constraints or color figure charges

- Immediate publication on acceptance

- Inclusion in PubMed, CAS, Scopus and Google Scholar

- Research which is freely available for redistribution

Submit your manuscript at www.biomedcentral.com/submit
Biomed Central 